Georgetown University Law Center

Scholarship @ GEORGETOWN LAW

2018

\title{
Tackling Obesity and Disease: The Culprit Is Sugar; the Response Is Legal Regulation
}

Lawrence O. Gostin

Georgetown University, gostin@law.georgetown.edu

This paper can be downloaded free of charge from:

https://scholarship.law.georgetown.edu/facpub/2042

https://ssrn.com/abstract=3142248

Lawrence O. Gostin, Tackling Obesity and Disease: The Culprit Is Sugar; the Response Is Legal Regulation, Hastings Center Rep., Jan./Feb., at 5-7 (2018)

This open-access article is brought to you by the Georgetown Law Library. Posted with permission of the author. Follow this and additional works at: https://scholarship.law.georgetown.edu/facpub 


\section{Tackling Obesity and Disease: The Culprit Is Sugar; the Response Is Legal Regulation}

by Lawrence $\bigcirc$. Gostin

$\mathrm{I}$ $\mathrm{t}$ is staggering to observe the new normal in America: 37.9 percent Lof adults are obese, and 70.7 percent are either obese or overweight. One out of every five minors is obese. The real tragedy, of course, is the disability, suffering, and early death that devastates families and communities. But all of society pays, with the annual medical cost estimated at $\$ 147$ billion. The causal pathways are complexpoor diets and sedentary lifestyles. But if we drill down, sugar is a deeply consequential pathway to obesity (and to dental disease), and the single greatest dietary source is sugar-sweetened beverages (SSBs) — sodas, fruit drinks, energy drinks, and specialty coffees with added sugar, corn syrup, sucrose, fructose, glucose, or honey. Socioeconomic class drives SSB consumption, exacerbating unconscionable health disparities. ${ }^{1}$

The beverage industry for years has waged a "coordinated war" against public health regulation. ${ }^{2}$ Corporations surreptitiously funded misleading research, hid industry research showing profound harms, spent lavishly on political lobbying, and formed faux grass-roots organizations against any attempt to limit SSB sales. $^{3}$ When compared to "Big Tobacco," which is rightfully demonized, "Big Food" is better funded, more politically connected, and has greater influence.

Yet sugar has no nutritional value and does not trigger feelings of satiation. On any given day, half the population consumes SSBs. Multiple studies find major links between SSBs and weight gain, resulting in diabetes, cancers, and cardiovascular disease. One study found that for each twelve-ounce soda children consumed per day, the odds of becoming obese increased by 60 percent. ${ }^{4}$ It is during one's youth that taste preferences are developed and lifetime dietary habits are formed. And children and adolescents are the market beverage companies covet-the next generation of consumers.

The copious amount of sugar in the American diet is no accident. Industry practices and regulatory failures have fueled this explosion. Yet there are sensible, effective interventions that would create the conditions for healthier behaviors. What are the key interventions, and how can we overcome the social, political, and constitutional roadblocks? Tobacco control offers a powerful model, suggesting that success requires a suite of interventions working in concert: labeling, warnings, taxation, portion sizes, product formulation, marketing restrictions, and bans in high-risk settings such as schools and hospitals. For example, public education combined with multiple interventions reduced SSB consumption in one Maryland county by 20 percent. ${ }^{5}$ Each intervention deserves detailed analysis, but I'm kick-starting scholarly and policy conversation by systematically laying out the major legal tools.

\section{Advertising Restrictions: Commercial Speech}

hildren and adolescents are bom-
barded with marketing for SSBsnot only on television but also on social media, in children's games ("advergames"), and through contests with SSBs as prizes. Companies use appealing figures, such as Disney characters, with marketing campaigns fully integrated with common themes across multiple promotional platforms. The sheer size and strategic coordination of SSB marketing reveals the industry's intentions to drive SSB sales, especially among children and adolescents.

Unlike in progressive jurisdictions around the globe, in the United States, marketing sugary foods is virtually unregulated. ${ }^{6}$ We rely on voluntary but mostly unkept promises from industry. In 2006, in response to public concern, the industry announced self-regulation, promising to change the ratio of food and beverage advertising directed to children to encourage healthier eating. Although companies did reduce ad campaigns targeted to children, they still spent $\$ 866$ million in 2013 to advertise unhealthy drinks-more than four times the amount spent to promote water and 100 percent juice. Some companies, including Pepsi, Red Bull, and Snapple, actually increased youth marketing. ${ }^{7}$

Government seems unwilling to regulate advertising of SSBs due to industry influence and the belief that the First Amendment protects the freedom to market unhealthy products. Although the commercial speech doctrine expressly excludes speech targeting children, proving that a commercial is targeted at children is hard. Advertisements in popular television shows, at sporting events, in magazines, and even in games and social media reach both adults and youth. The Supreme Court has become 
more aggressive in defending commercial speech, even protecting the world's most dangerous product, tobacco.

Do corporations that spend lavishly to market products they know are unhealthy have a constitutional right to free speech and to exemption from public health regulation? Throughout American history until 1985, the Supreme Court did not grant commercial speech any First Amendment protection; when it finally did, the Court gave corporations decidedly lower levels of protection. No other country follows the logic of the modern Supreme Court. That is "American Exceptionalism" of dubious distinction.

\section{Labeling and Warnings: Compelled Speech}

$T^{\mathrm{t}}$ he Nutrition Labeling and Education Act of 1990 required most processed foods and beverages to be labeled with a nutrition facts panel, but the current system confuses consumers. The FDA planned to launch a new system in 2018, including larger font and disclosure of serving sizes and added sugars, but the Trump administration has delayed implementation until 2020 or 2021. Even the new nutritional panel does not go far enough. The United Kingdom's traffic light system requires vivid red warnings for excess sugar, sodium, and unhealthy fats. Consumers don't want to buy, and companies don't want to market, foods bearing large red lights on the package.

Graphic warnings have been particularly effective. Australia's plain packaging law (prohibiting branding, such as logos, images, and colors, on packages of cigarettes and other tobacco products), for example, significantly lowered tobacco sales, and research demonstrates that warnings would drive down sales of SSBs. In 2015, San Francisco enacted a safety warning on SSB ads. But in September 2017, a federal appellate court issued an injunction, saying the city probably violated the First Amendment by compelling companies to make controversial and burdensome disclosures. Never mind that San Francisco's language ("WARNING: Drinking beverages with added sugars contributes to obesity, diabetes, and tooth decay") was truthful and scientifically grounded. The court relied on FDA guidance that SSBs in moderation can be part of a healthy diet. That is true for virtually any food, but it doesn't change the fact that sugar has no nutritional value and has a unique role in obesity, diabetes, and dental caries. Commercial marketing and corporations' profit motives ought not be conflated with constitutionally protected political and artistic expression. Corporations are not persons, and money is not speech.

\section{SSB Taxes: Politics or Public Health?}

axes create powerful disincentives
for purchasing SSBs. The World Health Organization recommends raising prices by 20 percent to lower consumption, improve nutrition, and raise revenue for public health. Eight U.S. jurisdictions have adopted soda taxes, covering more than eight million people. Evidence from early adopters shows that taxes drive healthier consumption patterns. Berkeley's one-penny-per-ounce tax reduced sales by 21 percent in lowincome neighborhoods in the first year alone. Mexico's one-peso-per-liter tax spurred a 5.5 percent reduction in the first year and 9.7 percent reduction in the second year, with the largest declines among low socioeconomic groups. ${ }^{8}$

The United Kingdom's new graduated levy on SSBs is yielding yet another powerful impact: soda manufacturers are reformulating their beverages to significantly reduce the sugar content. Such product reformulation-whether incentivized or mandatory-helps reduce overconsumption of sugars at the societal level and marks a movement away from the longstanding notion that consumption is purely a matter of individual responsibility. While the public has become accustomed to copious quantities of sugar in beverages, they would barely notice a slow, gradual decline over years. That is the approach countries are taking with sodium and unhealthy fats. ${ }^{9}$
The political calculation is subtle. Chicago withdrew its SSB tax after a year, succumbing to industry lobbying. Yet Philadelphia had a winning strategy, selling the tax not as a public health measure but as a revenue generator for schools and urban development.

\section{Portion Size: "Nanny Bloomberg"}

Dortion sizes have risen dramatically. 1 In the 1950s, standard soft-drink bottles were 6.5 ounces; by the early 1990s, 20-ounce plastic bottles became the norm, and today Big Gulps have exploded to 42 ounces. A 20-ounce CocaCola, for example, contains 65 grams of added sugar. In the 1970s, SSBs comprised 4 percent of daily calorie intake; by 2001 , they rose to 9 percent, with youth averaging 224 empty calorizes daily.

Given the steep size increase in soda bottles and fountain drinks, regulating portion size would appear to be a natural intervention. Think again. In 2012, "Big Beverage" companies funded and mobilized community opposition to New York City's ban on selling SSBs in portions larger than 16 ounces. Six business associations sued. Public opposition was fierce, linking the rule to "Nanny Bloomberg." 10 New York's highest court ultimately struck down the rule, holding that the city's board of health had, by issuing the ban, trespassed on the elected city council's authority. Given the evidence linking portion size to weight gain and chronic disease, the court's reasoning was puzzling: the board had the power to ban "inherently harmful" 11 foods, but SSBs did not fall into that category.

This much we know. SSBs have no nutritional value and are highly correlated with weight gain and chronic disease. The impacts are especially felt in low-income neighborhoods and among minorities and young people. And we understand the tactics of Big Beverage companies to mislead the public while donning the mantle of liberty-spouting about personal autonomy, parental responsibility, limited government, low taxation, and free speech. This leaves society in a bind. The public is 
bombarded with deceptive advertising, while fast food outlets flourish. Public health agencies have their hands tied by the forces of politics, constitutionalism, industry spending, and corporate personhood. America has placed the value of individualism on a pedestal, and the results mean that more people are coping with chronic diseases and dying prematurely. For the first time in history, the next generation may live shorter lives than their parents. Why not try another way, placing the common good as a high value? A good place to start is to take action against the major harms wrought by the pervasive presence of sugar in the American diet.

1. "Get the Facts: Sugar-Sweetened Beverages and Consumption," Centers for Disease Control and Prevention, https://www.cdc. gov/nutrition/data-statistics/sugar-sweetenedbeverages-intake.html.
2. A. Lappe and C. Bronsing-Lazalde, "How to Win against Big Soda," New York Times, October 15, 2017.

3. C. E. Kearns, D. Apollonio, and S. A. Glantz, "Sugar Industry Sponsorship of Germ-Free Rodent Studies Linking Sucrose to Hyperlipidemia and Cancer: An Historical Analysis of Internal Documents," PLoS Biology 15, no. 11 (2017): e2003460.

4. D. S. Ludwig, K. E. Peterson, and S. L. Gortmaker, "Relation between Consumption of Sugar-Sweetened Drinks and Childhood Obesity: A Prospective, Observational Analysis," Lancet 357 (2001): 505-508.

5. M. B. Schwartz et al., "Association of a Community Campaign for Better Beverage Choices with Beverage Purchases from Supermarkets," JAMA Intern Medicine 177 (2017): 666-74.

6. D. M. Studdert, J. Flanders, and M. M. Mello, "Searching for Public Health Law's Sweet Spot: The Regulation of Sugar-Sweetened Beverages," PLoS Medicine 12, no. 7 (2015): e1001848.
7. "Sugary Drinks Facts: Food Advertising to Children and Teens Score," Rudd Center for Food Policy and Obesity, 2014, http:// www.sugarydrinkfacts.org/.

8. S. A. Roache and L. O. Gostin, "The Untapped Power of Soda Taxes: Incentivizing Consumers, Generating Revenue, and Altering Corporate Behavior," International Journal of Health Policy \& Management 6 (2017): 1-5.

9. L. O. Gostin et al., "Legal Priorities for Prevention of Non-communicable Diseases: Innovations from WHO's Eastern Mediterranean Region," Public Health 144 (2017): 4-12.

10. L. O. Gostin, "Bloomberg's Health Legacy: Urban Innovator or Meddling Nanny," Hastings Center Report 43, no. 5 (2013): 19-25.

11. In the Matter of New York Statewide Coalition of Hispanic Chambers of Commerce v. New York City Department of Health and Mental Hygiene (2014), http://www.nycourts. gov/ctapps/Decisions/2014/Jun14/134opn14Decision.pdf.

DOI: 10.1002/hast.804 